\title{
Cerebral blood flow and cerebrovascular response to acetazolamide in patients with chronic alcoholism
}

\author{
M Oishi, Y Mochizuki, T Takasu
}

\begin{abstract}
Cerebral blood flow and cerebrovascular response to acetazolamide were studied in 12 patients with chronic alcoholism and 12 age matched healthy controls. Blood flows in the cerebral cortex, thalamus, and putamen were significantly lower in the chronic alcoholic group than in the healthy control group. The increase in blood flow caused by acetazolamide did not show any significant difference between the two groups. These findings suggest that the decreased cerebral blood flow in chronic alcoholism is due to decreased cerebral metabolism.
\end{abstract}

(F Neurol Neurosurg Psychiatry 1997;63:100-102)

Keywords: cerebral blood flow; alcoholism; acetazolamide

Cerebral blood flow has been reported to be decreased in patients with chronic alcoholism ${ }^{1-4}$ but the cerebrovascular response to acetazolamide in such patients has not yet been reported. To determine the effects of chronic alcoholism on regional cerebral blood flow and cerebrovascular response to acetazolamide, we performed a xenon CT study in patients with chronic alcoholism and compared cerebral blood flow and response to cerebrovascular acetazolamide between this group and healthy controls.

Department of

Neurology, Nihon

University, School of

Medicine

M Oishi

Y Mochizuki

T Takasu

Correspondence to: Dr M Oishi, Department of

Neurology, Nihon University

Nerima Hikarigaoka

Hospital, 2-11-1

Hikarigaoka, Nerima-ku,

Tokyo 179, Japan.

Received 13 November 1996 and in revised form 28 January 1997

Accepted 31 January 1997

Mean (SD) of regional cerebral blood flows

${ }^{\star} \mathrm{P}<0.05 ;{ }^{\star \star} \mathrm{P}<0.01 v$ healthy control group.
Materials and methods

We studied 12 men with chronic alcoholism (mean age 56 (SD 7)) and 12 age matched healthy men who did not drink alcohol (mean age 57 (SD 6)). All subjects gave their informed consent. The patients fulfilled the DSM-IV criteria of alcohol dependence 5 and did not have any other relevant diseases (head trauma, depression, seizures, neurological complications of chronic alcoholism) or any significant abnormality on head CT and blood tests (hepatic function and standard blood biochemistry and haematology tests). No patients had Wernicke-Korsakoff syndrome and their average score for the mini mental state examination $^{6}$ was 25 . Mean height was $165 \mathrm{~cm}$, mean weight $62.3 \mathrm{~kg}$, and mean blood pressure $138 / 88 \mathrm{~mm} \mathrm{Hg}$ in the chronic alcoholic group and these variables were not significantly different from the healthy control group. Any medications which may have affected cerebral blood flow or cerebral metabolism (including benzodiazepines) were discontinued two weeks before the study of cerebral blood flow. All patients drank alcohol the night before the cerebral blood flow examination but on the day of examination they did not drink alcohol until after the examination, which was performed in the afternoon.

Cerebral blood flow was measured by the stable xenon CT method. ${ }^{78}$ The mathematical modelling of Meyer $e t a l^{9}$ and the procedure of Fatouros $e t a l^{10}$ were used to generate paramet-

\begin{tabular}{|c|c|c|c|c|c|c|}
\hline & \multicolumn{2}{|c|}{$\begin{array}{l}\text { Regional blood flows ( } \mathrm{ml} / 100 \\
\text { g/min) }\end{array}$} & \multicolumn{2}{|c|}{$\begin{array}{l}\text { Absolute changes by acetazolamide } \\
\text { (ml/100 g/min) }\end{array}$} & \multicolumn{2}{|c|}{$\begin{array}{l}\text { Increase rates by acetazolamide } \\
(\%)\end{array}$} \\
\hline & Alcoholic & Control & Alcoholic & Control & Alcoholic & Control \\
\hline Frontal cortex & $52.8(9.3)^{\star \star}$ & $70.9(9.8)$ & $31.9(6.6)$ & $37.4(7.4)$ & $60.4(9.5)$ & $52.8(9.1)$ \\
\hline Temporal cortex & $51.9(9.2)^{\star \star}$ & $68.4(9.6)$ & $32.9(6.8)$ & $38.8(6.6)$ & $63.4(9.0)$ & $56.7(8.4)$ \\
\hline Parietal cortex & $51.1(9.0)^{\star \star}$ & $67.4(9.5)$ & $29.5(6.6)$ & $35.7(6.5)$ & $57.7(8.3)$ & $53.0(7.8)$ \\
\hline Occipital cortex & $49.8(8.8)^{\star \star}$ & $66.6(9.5)$ & $27.7(6.5)$ & $33.6(6.3)$ & $55.6(8.9)$ & $50.5(8.2)$ \\
\hline Anterior cingulate cortex & $52.2(9.2)^{\star \star}$ & $70.4(9.7)$ & $31.3(6.1)$ & $36.9(6.8)$ & $60.0(9.2)$ & $52.4(8.9)$ \\
\hline Frontal white matter & $24.5(7.4)$ & $27.4(7.5)$ & $10.8(2.8)$ & $12.0(3.0)$ & $44.2(7.1)$ & $43.8(7.4)$ \\
\hline Occipital white matter & $23.1(7.0)$ & $25.9(7.2)$ & $11.1(2.9)$ & $12.3(3.1)$ & $48.2(7.6)$ & $47.3(7.9)$ \\
\hline Thalamus & $57.2(9.4)^{\star \star}$ & $71.5(9.2)$ & $32.3(5.3)$ & $35.2(5.1)$ & $56.4(8.9)$ & $49.2(7.8)$ \\
\hline Caudate nucleus & $78.4(9.5)$ & $82.3(9.2)$ & $33.2(5.4)$ & $31.6(4.9)$ & $42.3(6.5)$ & $38.4(6.2)$ \\
\hline Putamen & $72.4(8.7)^{\star}$ & $80.2(8.4)$ & $39.0(5.6)$ & $42.3(5.9)$ & $53.8(8.4)$ & $52.7(8.1)$ \\
\hline
\end{tabular}




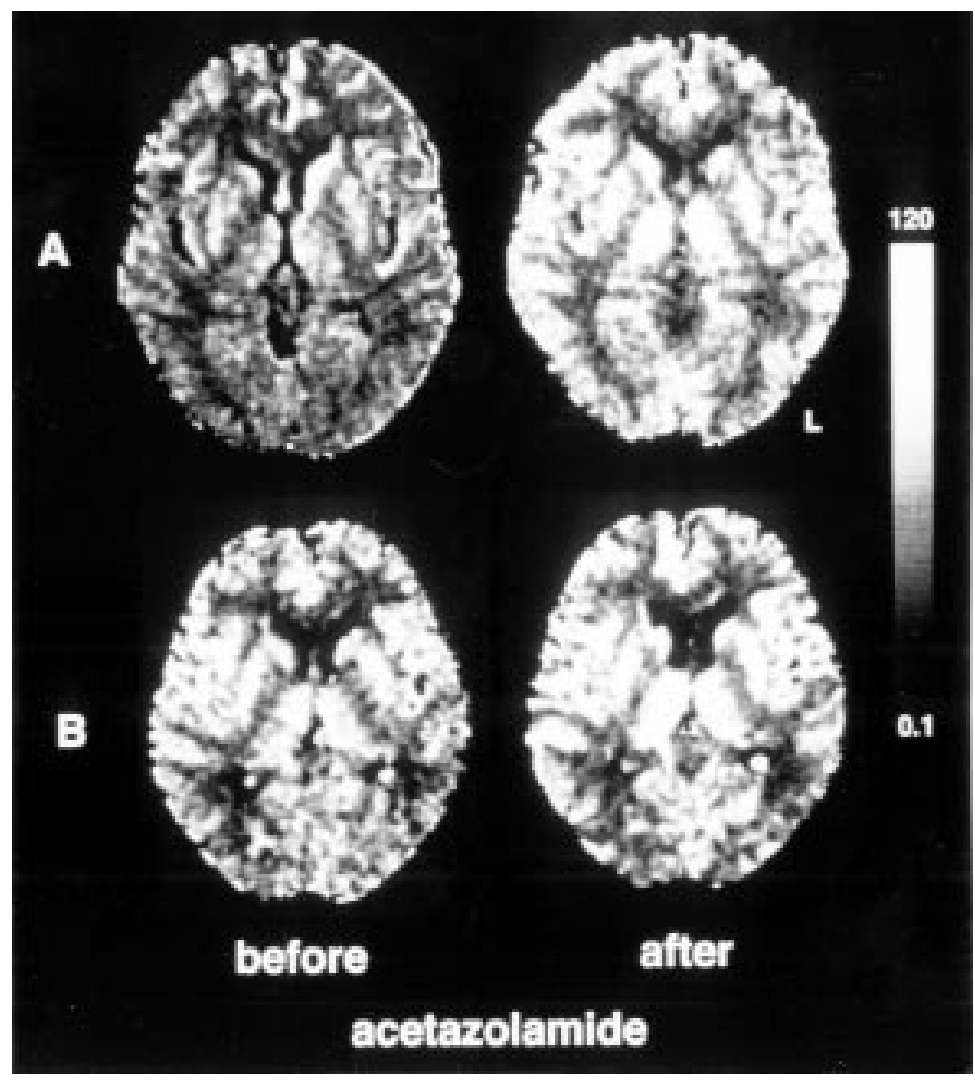

Xenon CT before and after intravenous injection of acetazolamide. $(A)$ a patient with chronic alcoholism, (B) a healthy control. Before injection of acetazolamide, the blood flows in the cerebral cortex, thalamus, and putamen were lower in $(A)$ than in $(B)$. Cerebrovascular response to acetazolamide was high in both $(A)$ and $(B)$.

ric maps. The basal ganglia section and the lateral ventricle section parallel to the orbitomeatal line were selected as the regions of interest. The subjects inhaled room air followed by a mixture of $30 \%$ xenon and $50 \%$ oxygen for three minutes. Serial scanning was performed, once before xenon inhalation, three times in the wash in process, and five times in the wash out process of five minutes. The serial scanning programme consisted of 18 scans with nine serial scans on each section. The xenon concentration in the end tidal expired gas was continuously recorded by the thermoconductivity method. We used the xenon delivery and analysis system AZ-7000 model, Anzai Sogyo, Tokyo, Japan and CT equipment from PreSage, Yokogawa Medical Systems, Tokyo, Japan. Values for regional cerebral blood flow were obtained with the procedure of Kawamura et al. ${ }^{11}$ Xenon CT examinations were performed before and 20 minutes after intravenous injection of $17 \mathrm{mg} / \mathrm{kg}$ acetazolamide.

Statistical analysis of the cerebral blood flows was performed by Mann-Whitney $U$ test.

\section{Results}

The figure shows xenon CT examination before and after intravenous injection of acetazolamide. The table shows the mean (SD) of the blood flows. Blood flows in the cerebral cortex, thalamus, and putamen were significantly lower in the chronic alcoholic group than in the healthy control group. The absolute changes and the increased rates of blood flows did not show any significant differences between the two groups.

\section{Discussion}

Cerebral blood flow has been reported to be decreased in patients with chronic alcoholism $^{1-4}$ but only one study used the xenon CT method. ${ }^{12}$ The main advantage of this method is that it provides relatively high resolution and quantitative information on regional cerebral blood flow coupled with anatomy by CT. ${ }^{8}$ Hata $e t ~ a l^{12}$ reported that local cerebral blood flows were reduced throughout all grey matter in patients with chronic alcoholism without Wernicke-Korsakoff syndrome. However, the present study showed that the blood flow in the cerebral cortex, thalamus, and putamen were reduced but that in the caudate nucleus was normal. The normal blood flow in the caudate nucleus may be due to the few patients studied so far.

The mechanism of decreased cerebral blood flow in patients with chronic alcoholism has not yet been elucidated ${ }^{23-15}$ although it is thought to be due to decreased cerebral metabolism. ${ }^{2}{ }^{15}$ Because the effects of chronic alcoholism on metabolism are not uniformly distributed in the present study, the result cannot be explained by the possibility that the patients with chronic alcoholism are more sensitive to the anaesthetic effects of xenon. The present study showed that the cerebrovascular response to acetazolamide was normal in such patients. Acetazolamide is considered to dilate the cerebral arterioles by inhibiting the carbonic anhydrase in the red blood cells and increasing carbon dioxide in the arterioles. ${ }^{16}$ Although the possible influence of early withdrawal effects on cerebral blood flow cannot be excluded, the result of the present study suggests that the reduced blood flow is not due to vascular problems such as arteriosclerosis in patients with chronic alcoholism.

1 Melgaard B, Henriksen L, Ahlgren P, Danielsen UT, Sørensen H, Paulson OB. Regional cerebral blood flow in chronic alcoholics measured by single photon emission computerized tomography. Acta Neurol Scand 1990;82:8793.

2 Mathew RJ, Wilson WH. Substance abuse and cerebral blood flow. Am f Psychiatry 1991;148:292-305.

3 Erbas B, Bekdik C, Erbengi G, Enünlü T, Aytac S, Kumbasar H, Dogan Y. Regional cerebral blood flow changes in chronic alcoholism using Tc-99m HMPAO SPECT; comparison with CT parameters. Clin Nucl Med 1992;17:1237 .

4 Nicolás JM, Catafau AM, Estruch R, Lomeña FJ, Salamero M, Herranz R, Monforte R, Cardenal C, Urbano-Marquez A. Regional cerebral blood flow-SPECT in chronic alcoholism: relation to neuropsychological testing. $f$ Nucl Med 1993;34:1452-9.

5 Schuckit MA, Helzer JE, Cottler JE, Crowley T, Nathan PE, Woody GE. Substance-related disorders. In: Frances A, Pincus HA, First MB, eds. Diagnostic and statistical manual of mental disorders. 4th ed. Washington, DC: American Psychiatric Association, 1994:175-272.

6 Folstein MF, Folstein SE, McHugh PR. "Mini-mental state" practical method for grading the cognitive state of patients for the clinician. F Psychiat Res 1975;12:189-98.

7 Johnson DW, Stringer WA, Marks MP, et al. Stable xenon CT cerebral blood flow imaging: rationale for and role in clinical decision making. AfNR Am f Neuroradiol 1991;12. 201-13.

8 Oishi M, Mochizuki Y, Hara M, Du C-M, Takasu T. Effects of intravenous L-dopa on P300 and regional cerebral blood flow in parkinsonism. Int $\mathcal{F}$ Neurosci $1996 ; 85: 147-54$.

9 Meyer JS, Shinohara T, Imai A, Kobari M, Sakai F, Hata T, et al. Imaging local cerebral blood flow by xenon-enhanced computed tomography - technical optimization procedures. Neuroradiology 1988;30:283-92. 
10 Fatouros PP, Wist AO, Kishore PRS, DeWitt DS, Hall JA, Keenan RL, et al. Xenon/computed tomography cerebral blood flow measurements. Methods and accuracy. Invest Radiol 1987;22:705-12.

11 Kawamura J, Meyer JS, Ichijo M, Kobari M, Terayama Y, Weathers S. Correlations of leuko-araiosis with cerebral atrophy and perfusion in elderly normal subjects and demented patients. $f$ Neurol Neurosurg Psychiatry 1993;56: demented patients. F Neurol Neurosurg Psychiatry 1993;56: $182-7$

12 Hata T, Meyer JS, Tanahashi N, Ishikawa Y, Imai A, Shinohara $\mathrm{T}$, et al. Three-dimensional mapping of local cerebral perfusion in alcoholic encephalopathy with and without
Wernicke-Korsakoff syndrome. $\mathcal{f}$ Cereb Blood Flow Metab 1987;7:35-44.

13 Samson Y, Baron J-C, Feline A, Bories J, Crouzel C. Local cerebral glucose utilization in chronic alcoholics: a positron tomographic study. $\mathcal{F}$ Neurol Neurosurg Psychiatry 1986;49: $1165-70$.

14 Gorelick PB. Alcohol and stroke. Stroke 1987;18:268-71.

15 Sachs H, Russell JAG, Christman DR, Cook B. Alteration of regional cerebral glucose metabolic rate in non-Korsakoff chronic alcoholism. Arch Neurol 1987;44:1242-51.

16 Frankel HM, Gracia E, Malik F, Weiss JK, Weis HR. Effect of acetazolamide on cerebral blood flow and capillary patency. F Appl Physiol 1992;73:1756-61. 